\title{
The Relationship Between Stress Levels with the Incidence of Hypertension in Menopausal Women
}

\author{
Huda Rohmawati, Siti Aminah, Sunaningsih, Rony D., Wismoadi A. \\ Progam Studi Pendidikan Profesi Bidan, Universitas Kadiri-Indonesia \\ Email: huda.rohma@unik-kediri.ac.id
}

\section{ARTICLE INFO}

Article history:

Received: March 8, 2021

Revised: April 24, 2021

Accepted: May 12, 2021

Keywords:

Hypertension,

Stress levels,

Menopausal

Women.

\begin{abstract}
Background: Menopause is the cessation of the last menstruation that occurs in the climacteric period and the hormone estrogen is no longer formed. The older the age, the more diseases suffered at the age of menopause, such as hypertension. Hypertension is a condition when a person experiences an increase in blood pressure either slowly or suddenly. The factors that cause hypertension are mostly due to stress. This study aims to determine the relationship between stress levels with the incidence of hypertension in postmenopausal women. Methods: The design of this research is correlational analytic. The sample is 50 respondents with the Stratified Random Sampling technique. The instrument used is a questionnaire. The results of the study were analyzed using the Spearman rank statistical test. Result: The results showed that there were 24 people $(48.0 \%)$ with moderate stress levels and 18 people (36.0\%) experiencing Stage I Hypertension. The results of the Spearman's Rank correlation test showed that the value of value $=0.000$ was smaller than the value of $=0.05$ so that $\mathrm{H} 0$ is rejected and $\mathrm{H} 1$ is accepted, meaning that there is a relationship between stress levels and the incidence of hypertension in postmenopausal women. Conclusion: It is expected that respondents will increase their knowledge about how to deal with stress so that they do not experience stress at a severe level so that it does not have a bad impact on them.
\end{abstract}

\section{Introduction}

Menopause is the cessation of the last menstruation that occurs in the climacteric period and the hormone estrogen is no longer formed, so it is a point in time and generally occurs at the age of 45-55 years (Pieter, 2010). Menopause usually occurs at the age of 50 years, but can occur normally in women who are 40 years old. Menopause is generally long and the amount of blood that comes out in the menstrual cycle tends to vary, not as usual. In women, menstrual activity stops suddenly, but usually stops gradually (both in number and duration) and the intervals between the 2 cycles become closer and less frequent. This irregularity occurs for 2 to 3 years before the cycle finally stops (Irawati, 2010). The human life cycle consists of conception, infant, child, adolescent, childbearing age to old age (Febrina, 2010). In early adolescence, women experience menstruation every month and last throughout the reproductive period. Furthermore, women experience tiring pregnancy and breastfeeding, this phase will end with the arrival of menopause which generally occurs at the age of 45 years (Siagian, 2015). 
The older a person gets, the more diseases that appear and often suffer, especially at the age of menopause. Hypertension or "high blood pressure" is a condition when a person experiences an increase in blood pressure either slowly or suddenly. The diagnosis of hypertension is made when a person's systolic blood pressure remains at $140 \mathrm{mmHg}$ or more.

Of the population of women aged 45-50 years who are classified as menopausal age some experience high blood pressure experienced by women all over the world, around (70-80\%) European women, $(60 \%)$ in America, (75\%) in Malaysia, (18\%) in China, (10\%) in Japan and in Indonesia (10\%). In East Java, there are (75\%) postmenopausal women experiencing changes in blood pressure and more menopausal women experiencing an increase in blood pressure from normal to high.

Based on the results of an initial survey conducted in the Sukorame Health Center Work Area, Kediri City, it was found that the number of menopausal women at the corner posyandu in 2016 was 50 people with hypertension, 31 people, 2017 hypertension became 35 people, 2018 was 44 people, 2019 the number of menopausal women was 57 people had hypertension as many as 50 people $(87.71 \%)$. From the data above, it is known that most menopausal women experience hypertension, so it can be concluded that since the last 3 years there has been an increase in menopausal women who have hypertension.

The factors that cause hypertension are mostly due to stress. During periods of stress, there is a release of neurotransmitters (neurotransmitters are chemicals in the body that carry messages to and from nerves) from the adrenal glands, the medulla. The adrenal medulla secretes two types of neurotransmitters, namely epinephrine or referred to as adrenaline and norepinephrine (noradrenaline), the adrenal glands produce more stress hormones than estrogen, resulting in a decrease in estrogen (Nasution I. K., 2017)

Hypertension can be prevented by avoiding the factors that cause hypertension by regulating diet, the right lifestyle, avoiding coffee consumption, not smoking and alcohol, reducing excessive salt consumption, and adequate activities such as regular exercise and coping with stress (Dalimartha, 2018).

\section{Method}

This study is a correlational analysis, to determine the relationship between stress levels and the incidence of hypertension in postmenopausal women. The research was carried out in the Corner Village, the Working Area of the Sukorame Health Center, Kediri City. The sample in this study was 50 people.

The sampling technique used is probability sampling with the Stratified random sampling technique. The instrument used in this study was a questionnaire. The data analysis technique in this study used the Spearman Rank statistical test using the help of a computer program. 


\section{Results and Discussion}

Table 1. Stress levels in menopausal women

\begin{tabular}{lcc}
\hline Stress level & Total (n) & Percentage (\%) \\
\hline Normal & 8 & 16,0 \\
Light & 18 & 36,0 \\
Medium & 24 & 48,0 \\
Weight & 0 & 0 \\
\hline Total & 50 & 100
\end{tabular}

From table 1 it is found that almost half of the respondents experienced moderate stress levels, namely as many as $24(48.0 \%)$.

Tabel 2. Kejadian Hipertensi pada wanita menopause

\begin{tabular}{ccc}
\hline Hypertension Incidence & Total (n) & Percentage (\%) \\
\hline Normal & 11 & 22,0 \\
Pre Hypertension & 7 & 14,0 \\
Stage I & 18 & 36,0 \\
Stage II & 14 & 28,0 \\
\hline Total & 50 & 100
\end{tabular}

From table 2, almost half of the respondents experienced Stage I Hypertension, namely 18 $(36.0 \%)$.

Table 3. Relationship between stress levels and the incidence of hypertension in menopausal women

\begin{tabular}{|c|c|c|c|c|c|c|c|c|c|c|}
\hline \multicolumn{11}{|c|}{ Hypertension Incidence } \\
\hline \multirow[t]{2}{*}{$\begin{array}{l}\text { Tingkat } \\
\text { stress }\end{array}$} & \multicolumn{2}{|c|}{ Normal } & \multicolumn{2}{|c|}{$\begin{array}{c}\text { Pre } \\
\text { Hypertens } \\
\text { ion }\end{array}$} & \multicolumn{2}{|c|}{ Stage I } & \multicolumn{2}{|c|}{ Stage II } & \multicolumn{2}{|c|}{ Total } \\
\hline & $\mathrm{f}$ & $\%$ & $f$ & $\%$ & $\mathrm{~F}$ & $\%$ & $\mathrm{f}$ & $\%$ & $\mathrm{f}$ & $\%$ \\
\hline Normal & 7 & 14.0 & 0 & 0,0 & 1 & 2,0 & 0 & 0,0 & 8 & 16,0 \\
\hline Light & 4 & 8,0 & 6 & 12,0 & 4 & 8,0 & 4 & 8,0 & 18 & 36,0 \\
\hline Medium & 0 & 0,0 & 1 & 2,0 & 13 & 26,0 & $\begin{array}{l}1 \\
0\end{array}$ & 20,0 & 24 & 48,0 \\
\hline Weight & 0 & 0,0 & 0 & 0,0 & 0 & 0 & 0 & 0 & 0 & 0 \\
\hline Total & 11 & 22,0 & 7 & 14,0 & 18 & 36,0 & $\begin{array}{l}1 \\
4\end{array}$ & 28,0 & 50 & 100 \\
\hline$p=0,000$ & & & & $\alpha=0$, & & & & & &, 654 \\
\hline
\end{tabular}


Table 1 shows that almost half of the respondents experienced moderate stress as many as 24 people (48.0\%). Stress is a condition that is internal, which can be caused by a physical (body), or environmental, and social situations, which are destructive and uncontrolled (AAT Sriati, 2017). During periods of stress, estrogen levels drop. Adrenaline produces more stress hormones than estrogen. During this phase, when estrogen levels drop, blood vessel plaque builds up, which increases the risk of heart disease. After reaching menopause, estrogen levels in women decrease by up to $80 \%$ (Anjali, 2018).

Table 2 shows that almost half of the respondents had stage I hypertension (BP 140/90 $\mathrm{mmHg}-$ $150 / 90 \mathrm{mmHg}$ ) as many as 18 people (36.0\%). In line with increasing age, there is a decrease in the elasticity and stretchability of the large arteries. Aortic pressure increases very high with the addition of intravascular volume which slightly indicates blood vessel stiffness at menopause age (Geriatrics, 2018).

Hypertension is closely related to age, the older a person is, the greater the risk of developing hypertension. So that the prevalence of hypertension among the elderly and postmenopausal women is quite high, namely around $40 \%$ with mortality around $50 \%$ over the age of 60 years (Stockslager, 2018).

At the age of menopause, there will be various setbacks in the body's organs, therefore it is very easy to get diseases such as hypertension. This is also due to hormonal factors, during menopause the hormone estrogen can protect women from cardiovascular disease, levels of this hormone will decrease after menopause so that susceptible to hypertension.

Table 3 shows that almost half of postmenopausal women who experience stress will experience stage I hypertension as many as $18(36 \%)$ and stage II hypertension as many as $14(28 \%)$.

Based on the results of the Spearman Rho statistical test between the level of stress and the incidence of hypertension, it was found that value $=0.000$ is smaller than the value of $=0.05$ $(0.000<0.05)$ so that $\mathrm{H} 0$ is rejected and $\mathrm{H} 1$ is accepted, meaning that there is a relationship between stress levels and the incidence of hypertension in menopausal women. While the closeness of the relationship is seen from the results of the Correlation Coefficient $=0.654$, meaning that it has a strong close relationship between stress levels and the incidence of hypertension. The direction of the correlation/relationship is positive, meaning that the higher the stress level of menopausal women, the higher the experience of hypertension.

The stressful situation activates the hypothalamus which in turn controls two neuroendocrine systems, namely the sympathetic system and the adrenal cortex system. The sympathetic nervous system responds to nerve impulses and the hypothalamus, namely: Activating various organs and smooth muscles under its control. For example, it increases the heart rate and dilates the pupils. The sympathetic nervous system also gives signals to the adrenal medulla (dr. Suparyanto M.kes, 2011).

During periods of stress, there is a release of neurotransmitters (neurotransmitters are chemicals in the body that carry messages to and from nerves) from the adrenal glands, the medulla. The adrenal medulla secretes two types of neurotransmitters, namely epinephrine or referred to as adrenaline and norepinephrine (noradrenaline), the adrenal glands produce more stress hormones than estrogen, resulting in a decrease in estrogen (Nasution I. K., 2017).

Decreased production of estrogen to a critical level causes estrogen to no longer inhibit the formation of sufficient FSH and LH to cause an anovulatory cycle. As a result, FSH and LH (especially FSH) are subsequently produced in large and steady amounts. Estrogen is produced in subcritical amounts for a short time after menopause, but after a few years, when the last remaining primordial follicles become atretic, the production of estrogen by the ovaries drops to zero (Guyton, 2017).

After reaching menopause, estrogen levels in women decrease by up to $80 \%$. This is an important turning point in a woman's life. Many major changes that occur such as facial redness and feeling hot, low bone mass to osteoporosis. In addition, estrogen protects the heart and blood vessel system until menopause (Anjali, 2018).

Most of the respondents at the research site experienced moderate stress which could cause stage I hypertension compared to those with mild stress. This can be due to the fact that most of 
the respondents aged 50-55 years who are classified as elderly and have the status of IRT are more concerned with household work, and almost all respondents have basic education so that they have limited information about the importance of preventing stress and how to overcome hypertension. If a person experiences stress and it cannot be handled properly, it will have the potential for the occurrence of hypertension, especially during menopause. So it can be said that the higher the stress of a postmenopausal mother, the higher the incidence of hypertension.

\section{Conclusion}

There is a relationship between stress levels and the incidence of hypertension in postmenopausal women in the Pojok village, with a strong relationship strength and a positive correlation direction. Respondents are expected to increase their knowledge about how to deal with stress so that they do not experience severe stress or if they experience mild stress, they can be immediately overcome and in the end, it will not have a bad impact on themselves. It is hoped that health workers will be more proactive in conducting outreach to the community, especially mothers about the stress that mothers may experience in their daily lives and provide solutions to solving stress problems with medication or relaxation and activities such as gymnastics, social gatherings at the Posyandu.

\section{Acknowledgment}

The researcher wants to acknowledgment Kadiry University, especially the Health Science Faculty, for giving a chance for doing the research and composing the report

\section{References}

Anantasari, Ririn. 2019. The Effectiveness of Massage With Franjipani Scented Oil By Reducing Stress Levels in Menopausal Mothers in Dusun Jabon. Downloaded July 17, 2021, from http://www.lontar.ui.ac.id/125379.

Arief, Mansjoer. 2017. Capita Selecta Medicine. Media Aesculapius FKUI : Jakarta.

Arikunto, Suharsimi. 2016. Research Procedure Revised 2010 Edition. Rineka Cipta : Jakarta.

Baraas F. 2016. Molecular Cardiology: Free Radicals, Endothelial Dysfunction, Atherosclerosis, Antioxidants, Physical Exercise, and Cardiac Rehabilitation. Jakarta: Kardia Iqratama.

Baziad, A. 2018. Menopause and Andropause. Jakarta: Bina Pustaka

Foundation Brunner and Suddarth. 2006. Textbook of Internal Medicine 8th Edition. EGC: Jakarta.

Diputra, P, 2016. 7 Facts and Tips for Facing Menopause. downloaded July 21, 2021 from http://migasindonesia.net/download/index.php.option=comcontent\&task=viewwarticle\&art $\mathrm{id}=34$.

Corwin, A. 2015. Hypertension and its Complications, accessed on 02 July 2021 from www, Noncommunicable diseases, com/reference $543 \mathrm{htm}$

Elis Ofta Dwinawati, 2009. The Relationship between Stress Levels and Hypertension in the Elderly "Waluyo Husodo" Tulungagung.

Harianto, I. 2010. The Relationship between Stress Levels and Hypertension Incidences in the Elderly at the Majapahit Elderly Social Home in Mojokerto. Jombang BPPM STIKES PEMKAB. Jombang.

Hawadi D, 2010, Management of Stress, Anxiety, Depression, Jakarta, FKUI.

Joewono, Boedi S. 2007. Heart Disease. Airlangga University Press : Surabaya.

Kuntaraf, J.K. 2008. Sports Health Sources. Jakarta : Perc. Indonesian Adventists. 
Kuswardhani, T, 2008. Management of Hypertension in the Elderly. Martin, John. 2005. Heart Disease and Stroke. Bandung : CV. Miscellaneous.

Nugroho, Wahjudi. 2008. Gerontic Nursing. EGC: Jakarta.

Siburian, 2008. Overview of the incidence of hypertension and related factors, Thesis, FKM UI.

Suhartono, Imam. 2009. Heart Attack and Stroke. Gramedia Main Library Bandung 